\title{
MEASURING THE PERFORMANCE OF ASSETS: A REVIEW OF THE FACILITY CONDITION INDEX
}

\author{
Fulvio RE CECCONI (D), Nicola MORETTI (D), Mario Claudio DEJACO \\ Department of Architecture, Built Environment and Construction Engineering, Politecnico di Milano, \\ via G. Ponzio 31, Edificio 15 - Campus Bonardi, Milano 20133, Italy
}

Received 07 June 2017; accepted 07 September 2018

\begin{abstract}
Measurement of performances in asset management is an enabling factor to define an effective strategy. The scope of this research concerns the investigation on the Facility Condition Index (FCI): one of the most common metrics related to the built environment. The research aims at providing a critical review concerning the FCI and its use. The research methodology has been developed according to three steps: bibliographic research, bibliometric analysis and critical review. Most of the sources agree that FCI provides a reliable economic measurement of maintenance needs, though it must be tied to a strong condition assessment methodology. Moreover, different methodologies for computation of the deferred maintenance and the current replacement value can be found in literature and many researchers emphasised the limits of FCI when dealing with components characterised by a considerable difference in replacement costs. In conclusion, FCI is included in the wider framework of asset management business process.
\end{abstract}

Keywords: Facility Condition Index, FCI, performance measurement, KPI, asset management, facility management, maintenance management.

\section{Introduction}

Performance measurement in asset management, since the last few decades, has gained momentum as a powerful means for decision making (Alexander, 1992). Performance measurement can be intended both as an enabling factor for the successful achievement of the objectives of an organisation and as a learning process within the company (Amaratunga \& Baldry, 2000) for reaching a higher level of effectiveness in decision making and delivery of better services (Yang, Yeung, A. P. C. Chan, Chiang, \& D. W. M. Chan, 2010). The use of Key Performance Indicators (KPIs) eases decision making, allowing to synthesise phenomena related to the built environment, without losing the systemic value of information (Ladiana, 2007). According to the level of aggregation, information acquires different meanings corresponding to the management needs. In Facility Management (FM), for instance, three decision making levels corresponding to specific sets of KPIs can be identified: strategic, tactical and operational (Ente Italiano di Unificazione, 2018; Maltese, Dejaco, \& Re Cecconi, 2017).

Performance measurement is always tied to an assessment process, which can exploit a wide combination of metrics belonging to different disciplinary fields (Ama- ratunga, Baldry, \& Sarshar, 2000; Amaratunga \& Baldry, 2003). These metrics can be collected in a performance measurement framework which varies according to the phenomena to be measured (Douglas, 1996). In Architecture, Engineering, Construction and Operation (AECO), KPIs are exploited for measurement of performances mainly related to technical, functional and economic/financial issues (Amaratunga \& Baldry, 2003). Even if it has been demonstrated that economic and financial indicators are too narrow to achieve a comprehensive knowledge of assets' performances (Pärn, Edwards, \& Sing, 2017; Yang et al., 2010), they are widely used in Asset Management (AM). Thus, the aim of this research is to present a critical review concerning the Facility Condition Index (FCI): one of the most acknowledged financial indicators (Lavy, Garcia, \& Dixit, 2010, 2014a, 2014b). The FCI allows to quantify in a scale from 0 to 100 (where 0 represents the best value) the condition of an asset, based on the expense dedicated to maintenance operations, calculated as the ratio between the cost of Deferred Maintenance (DM) over the Current Replacement Value (CRV). The indicator can be applied at different scales: from a single component to an entire building in a portfolio (Maltese et al., 2017). The research scope concerns the extensive analysis

${ }^{*}$ Corresponding author. E-mail: nicola.moretti@polimi.it 
of international literature, carried out through an investigation on most known scientific literature archives (e.g. Scopus, Web of Science, Science Direct, Google Scholar). Through this analysis, 42 articles have been selected. These documents have been exploited to identify the most acknowledged definitions of the FCI, and to investigate possible drawbacks and advantages arising from its use. The underpinning question concerns the validation of an assets' evaluation procedure based on the calculation of few KPIs, able to represent crucial issues related to the management of the built environment (Dejaco, Re Cecconi, \& Maltese, 2017). The need to develop and refine this evaluation procedure comes from some considerations on the contemporary real estate market, more and more characterised by the need for efficiency and interoperability among stakeholders. Monitor of performances is a key issue to achieve better levels of asset management (Pärn et al., 2017; Cable \& Davis, 2005), within the context described above. Although, this is often hindered by fragmentation and peculiarity of information concerning the building process, characterised by a great number of actors (Eastman, Teicholz, Rafael, \& Kathleen, 2011). PAS 1192-2: 2013 (BSI, 2013) gives a common framework to be adopted in order to better coordinate and systematise organisations' information flow in the asset management procedures. Moreover, ISO 55000 series (ISO, 2014), defines performance measurement as a central factor to be considered for management of organisation' tangible goods, balancing opportunities, risks and expenses.

Given the above, starting from the standard definition of the FCI calculation methodology, issues related to the optimisation of expense for maintenance in a condition of scarce resources are tackled in the last section of this article.

\section{Research methodology}

Figure 1 describes main methodological steps accomplished. In this research the international literature concerning the FCI have been studied. The FCI is one of the most used indicators, describing the performance related to expense for maintenance operations on assets. A recognition of the literature in performance measurement based on economic metrics has been done first.

Main methodological steps (in Figure 1) are:

- the bibliographic research, concerning the research and selection of references in most recognised databases;
- the bibliometric analysis, concerning network analysis, trend analysis and categorisation by topic, typology of reference and type of FCI formula;

- the critical review on the FCI.

\subsection{Network analysis}

In order to provide a wider picture of literature on KPIs for asset and facility management, a network analysis has been carried out (Figure 2 and Figure 3).

For this purpose, references from Scopus and Web of Science database have been retrieved, and the VOSviewer software has been used for full counting of co-occurrence of keywords in references (Perianes-Rodriguez, Waltman, Jan, \& Eck, 2016). This software allows to identify the intensity of cited keywords (dimension of the circle) in a selected sample, in terms of number of co-occurrence and strength of connections among keywords (line width). For space reasons, here are presented the network analyses carried out on Scopus database. An extensive extraction of articles concerning KPIs in asset and facility management has been done first (Figure 2).

Afterwards, a more detailed analysis among publications specifically on FCI has been accomplished (Figure 3). Among the 134 references analysed, "key performance indicators", "benchmarking"; "maintenance", "construction industry" are the most recurrent terms. This suggests that a conspicuous literature have been published on these topics. Nevertheless, it is appropriate to underline that Figure 2 shows that "maintenance" is connected to the "budget control" keyword only through a weak connection.

Moreover, "budget control" keyword intensity is rather low, suggesting a scarce literature production addressing the issue of budget control in asset and facility management. For the representation in Figure 2, a minimum number of occurrence equal to 5 has been set. Among the 121 keywords matching the parameter, FCI does not appear. Therefore, further bibliographic researches have been carried out, looking for reference in Scopus directly connected to FCI. The research returned only 18 articles on which a network analysis of keywords has been accomplished, setting the minimum occurrence threshold equal to 2 . Figure 3 represents the results of this further analysis. The results confirm that FCI is related to strategic asset and facility management issues, despite the sample of references is very scarce. Therefore, the literature review has been extended to further databases not only connected to academia.

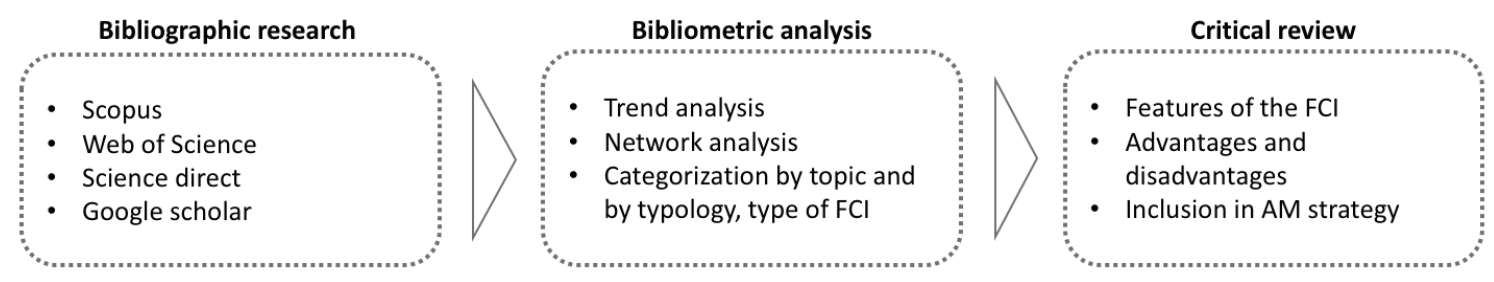

Figure 1. Research schema 


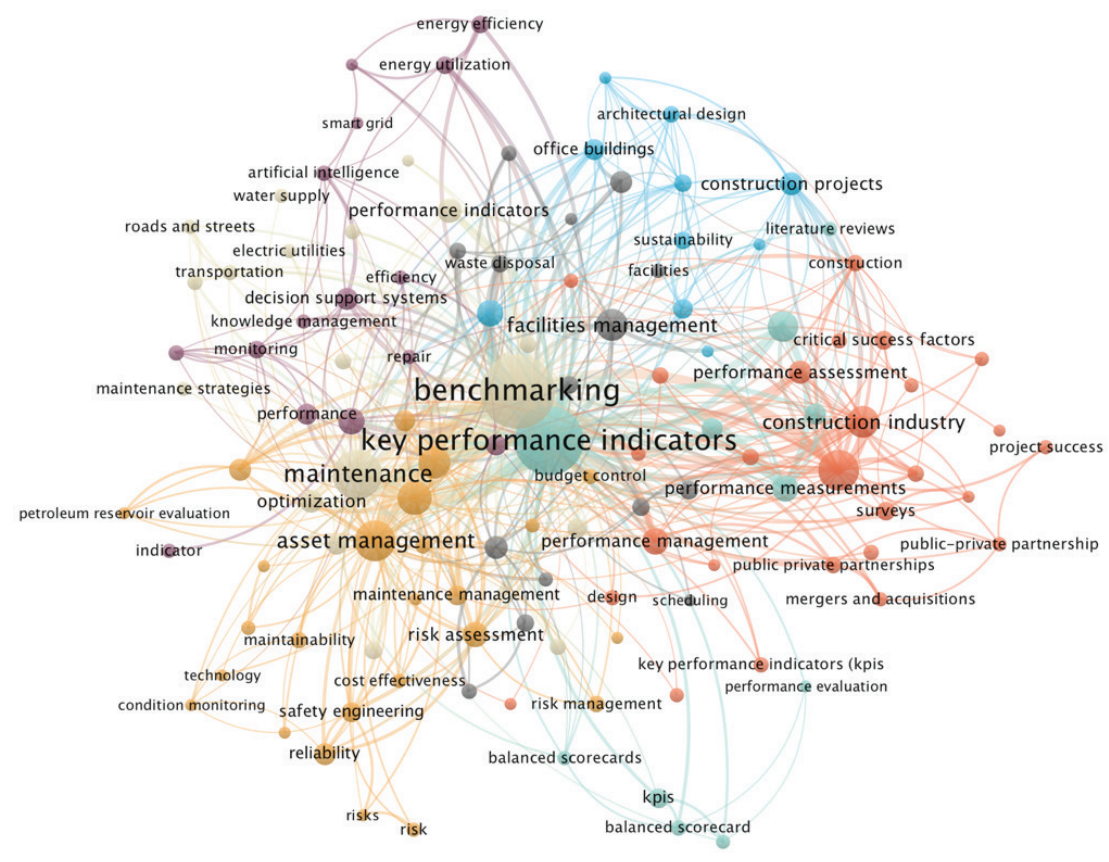

Figure 2. Visualisation of keywords co-occurrence in asset and facility management KPIs literature

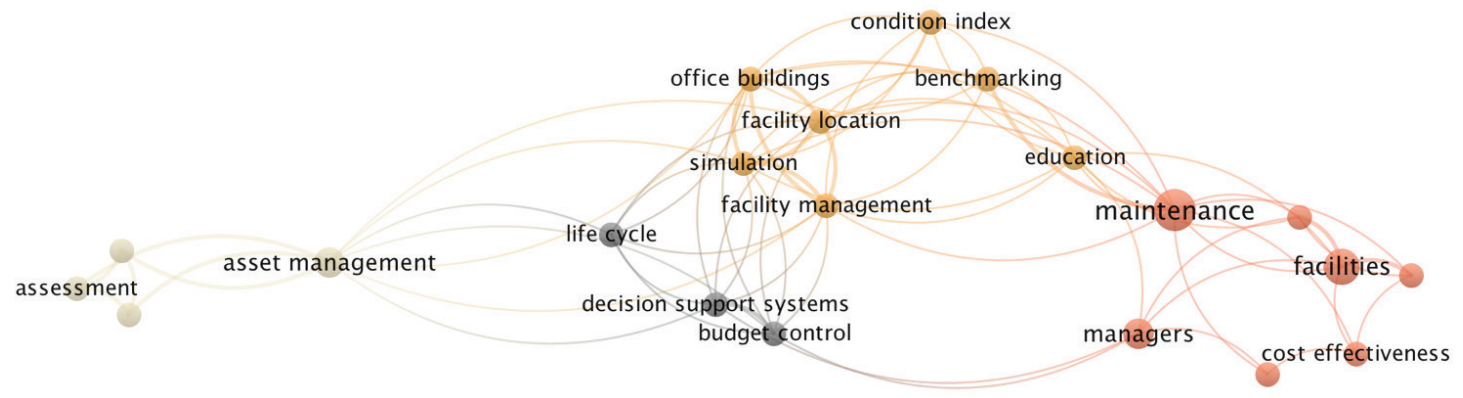

Figure 3. Visualisation of keywords co-occurrence in literature on FCI

While the articles have been retrieved mainly from Scopus, Web of Science, Science Direct and Google Scholar, they have been registered by year, author, provenance, typology of reference, type of dissertation and type of FCI described. Following this approach, it was possible to categorise the references as shown in Figure 4, Figure 5, Figure 6 and Figure 7.

\subsection{Extended literature review}

Google Scholar have been used to deepen the literature review on the Facility Condition Index. For this purpose, an additional set of keywords have been selected. The most frequent are: "Facility Condition Index", "Facility assessment", "deferred maintenance", "current replacement value", "KPI for asset management", "economic performance measurement", "economic real estate metrics". This is not an exhaustive list, but it is sufficient to outline the field of study. In details, 42 main references have been selected. After the trend analysis in Figure 4, demonstrating a slight increase in publications since the first time FCI appeared in literature, in Figure 5 references are classified according to the main topic discussed categorized according to the following four criteria:

- "KPI": is a categorisation for references dealing with FCI only in terms of description of the metric and its use;

- "CA strategy" refers to references dealing also with a Condition Assessment (CA) methodology tied to the computation of the FCI;

- "AM strategy" concerns those which address the issues related to the definition of a wider Asset Management (AM) strategy;

- "BIM process" concerns papers considering FCI as a metric to be integrated in a Building Information Modelling (BIM) process.

References have also been categorised by country. Despite Figure 5 and Figure 6 represent the correlation with two different criteria, in both the charts the most frequent provenance is from USA. This happens because 


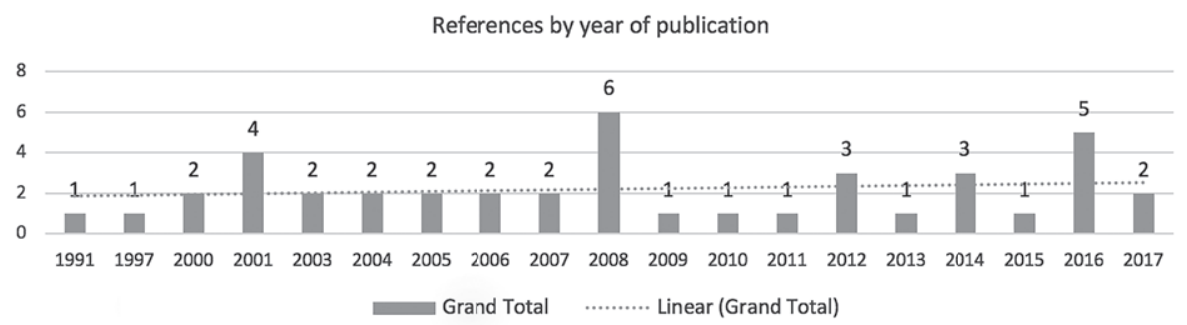

Figure 4. Publications from 1991 to 2017 (May 2017)

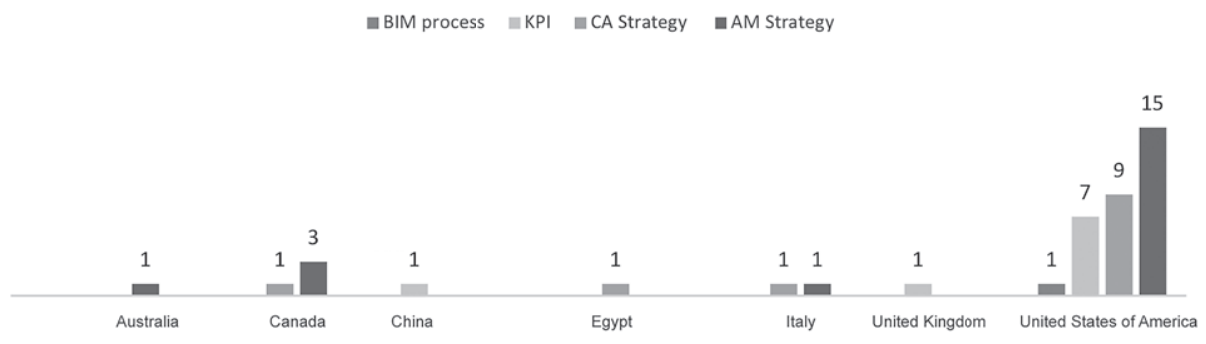

Figure 5. Reference classification by main topic and provenance

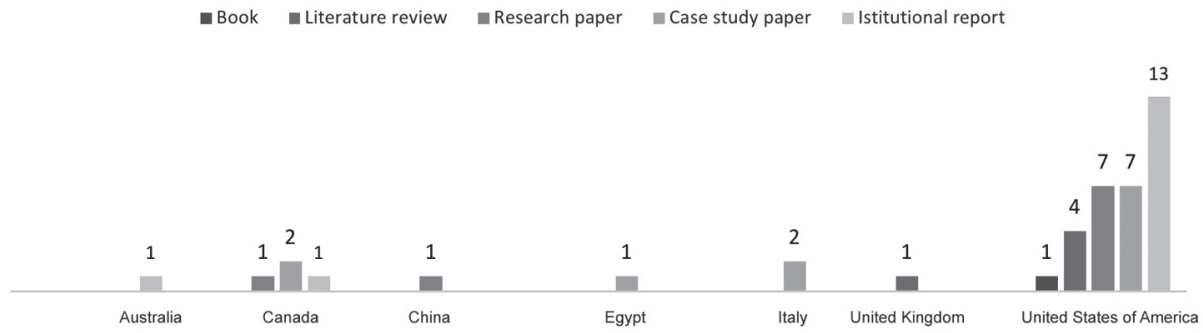

Figure 6. Reference classification by typology of reference and provenance

institutions as the Department of the Interior (U.S. Department of the Interior, 2017b) and the Department of Defence (U.S. Department of Defense, 2017) widely employ FCI for the assessment of large portfolios, or for monitoring facility management contractors. Moreover, the FCI is a metric encompassed in the standardised methodology for condition assessment of assets to be registered in the Federal Real Property Profile (FRPP) (General Service Administration, 2017): the Federal Asset Management Repository.

The classification in Figure 6, allows to verify that many references are not completely connected to academia, but rather to public institutions, which exploit the metric to implement the asset management strategy. This outcome is confirmed by the low sample availability for network analysis as well.

Despite some grey literature has been used (institutional reports), white papers, corporate reports and, in general, technical documentation have been neglected for the classification, since they cannot be considered as impartial sources to be exploited for the literature review.

\subsection{FCI and derived metrics}

The following step concerns a more detailed analysis of the contents of the references, namely an investigation on the definition of FCI formula. Despite most of the contributions assume as starting point for discussion the basic version given by National Association of College and University Business Officers (NACUBO) and Rush (1991), it is possible to spot some cases in which this version is modified to address specific issues. The somehow hidden modification may cause some biases in calculation of the final score and the clear loss of standardisation. Contributions have been classified according to the version of FCI considered. Figure 7 presents the results of this analysis. Even in this classification, references have been organised by country, showing a similar result as the previous bibliometric analysis. It is worthwhile, at this stage, to specify through Table 1 the criteria used for classification and related references.

Table 1 highlights that in most of the references analysed, both in research and in institutional reports, an ad- 


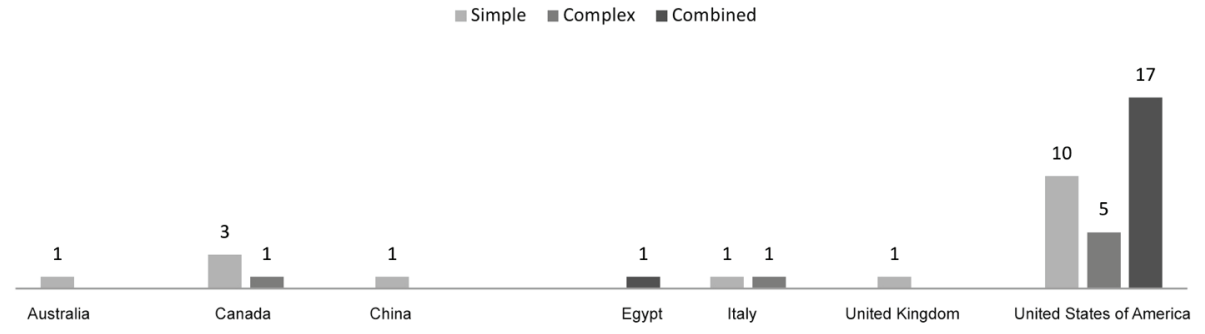

Figure 7. Classification of references by type of FCI described and provenance

Table 1. Criteria used for classification of FCI expression

\begin{tabular}{|l|l|l|}
\hline \multicolumn{1}{|c|}{ FCI } & \multicolumn{1}{|c|}{ Description } & \multicolumn{1}{c|}{ References } \\
\hline Simple & $\begin{array}{l}\text { Refers to the formula presented by } \\
\text { NACUBO and Rush (1991) }\end{array}$ & $\begin{array}{l}\text { (Rush, 1991; Kaiser, 1993; Fagan \& Kirkwood, 1997; AAPPA, 2000; Vanier, } \\
\text { 2000; Ho, E. H. W. Chan, Wong, \& M. Chan, 2000; Teicholz \& Edgar, 2001; } \\
\text { Brooks, 2004; Uzarski \& Grussing, 2008; IFMA, 2008; Roberts, 2009; Lavy } \\
\text { et al., 2010, 2014b; Bello \& Loftness, 2010; Attalla, MacDonald, \& Dunn, } \\
\text { 2012; Lavy, 2013; Karanja \& Mayo, 2016; Dejaco et al., 2017) }\end{array}$ \\
\hline Complex & $\begin{array}{l}\text { Differs from the previous for } \\
\text { the calculation methodology of } \\
\text { deferred maintenance and current } \\
\text { replacement value }\end{array}$ & $\begin{array}{l}\text { (Capital Asset Management - Asset Strategies, 2011; Geldermann \& Sapp, } \\
\text { 2007; Kaiser, 2009; Maltese et al., 2017; Quirk, 2006; Rashedi \& Hegazy, 2016; } \\
\text { Selman \& Schneider, 2004) }\end{array}$ \\
\hline Combined & $\begin{array}{l}\text { Indicators derived from the basic or } \\
\text { extended version of FCI, combined } \\
\text { with other metrics }\end{array}$ & $\begin{array}{l}\text { (Federal Facilities Council, 2001; Mills, 2001; NASA, 2003; Selman, 2003; } \\
\text { Cable \& Davis, 2005; U.S. Department of the Interior, 2005b, 2008a, 2008b, } \\
\text { 2016; Dempsey, 2006; Grussing \& Marrano, 2007; U.S. Department of the } \\
\text { Interior. National Park Service, 2012a, 2012b; Kincaid, 2013; Lavy et al., 2014, } \\
\text { 2014a; Kensek, 2015; Marzouk \& Awad, 2016) }\end{array}$ \\
\hline
\end{tabular}

justed version of the indicator is proposed, because of the high level of simplification of the basic form. Even though simplicity is probably one of the factors that makes the indicator so effective, it can be seen as a limitation to be balanced through corrective parameters or through the combination with other indicators. These corrective parameters widen the range of phenomena gathered by the indicator.

\section{FCI calculation methods}

The indicator, published in its first version by NACUBO and Rush (1991) thanks to the collaboration with Applied Management Engineering (AME) (Kaiser, 1993), was initially defined with the expression (1):

$$
F C I=\frac{D M}{C R V}[\%],
$$

where: $D M$ is the cost of Deferred Maintenance; $C R V$ is the Current Replacement Value.
The DM is defined as the monetary expenditure for the deferred maintenance operations and renewals on components, systems or the whole building, that should have been accomplished in a given period, but have been delayed. The Department of the Interior (DoI) defines DM as comprehensive of type of maintenance described in Table 2. On the other hand, CRV is defined as the replacement value of components, systems or the whole building (U.S. Department of the Interior, 2008b).

The result of the calculation ranges from 0 to 100 (where 0 is the best condition) and is usually organised in three or four levels, whose thresholds can slightly vary according to the type of asset under analysis:

- good: 0-5\%;

- fair: 5-10\%;

- poor: $10-30 \%$;

- critical: $30-100 \%$.

Worth to be notice that DoI, describes the calculation methodology for FCI in its institutional documents, though for the actual computation, it refers to the use of

Table 2. Types of maintenance comprehended in DM, according to DoI (U.S. Department of the Interior, 2008b) approach

\begin{tabular}{|l|l|}
\hline \multicolumn{1}{|c|}{ Type of maintenance } & \multicolumn{1}{c|}{ Definition } \\
\hline Corrective & Works for repair of broken or degraded components/assets \\
\hline Recurring & Planned maintenance in a timespan $(\mathrm{t}) 1$ year $<\mathrm{t}<10 y e a r s$ \\
\hline Component renewal & Planned maintenance in timespan $(\mathrm{t}) \mathrm{t}>10$ years \\
\hline Demolition & Removal including clean-up \\
\hline Rehabilitation & Renovation of a component/asset to extend its life \\
\hline Replacement & Substitution or exchange of an existing component/asset \\
\hline
\end{tabular}


the Facility Maintenance Management System (FMMS): the departmental facility management platform collecting data related to properties registered in the Federal Real Property Profile (FRPP) (General Service Administration, 2017).

Since the definition of its first version in Eq. (1), the indicator had been revised and other versions have been proposed. Recent versions of the FCI mainly differ in the calculation of the DM including, for instance, interventions accomplished to correct obsolescence due to the lack of compliance with codes. Other DM calculation methodologies are specific for the evaluation of historical assets or infrastructures.

The calculation of the performances related to the expense for maintenance operations can be adjusted in order to describe the overall performance of the asset or portfolio. Thus, the FCI can be tied to technical, functional and environmental parameters. The DoI, for instance, adopts a combination of indicators derived from the FCI to measure performances of high valuable and special assets. The DoI portfolio is composed by conventional buildings, as well as by infrastructures and heritage buildings. Therefore, the guideline for the implementation of the Site-Specific Asset Business Plan (U.S. Department of the Interior, $2005 \mathrm{~b}, 2008 \mathrm{~b}$ ), encourages the use of a combination of three variations of the FCI (2)(3)(4):

- the $\mathrm{FCI}_{\mathrm{dm}}$, as defined in Rush (1991) and in Eq. (1):

$$
F C I_{d m}=\frac{\text { Deferred Maintenance }(D M)}{\text { Current Replacement Value }(C R V)}[\%] \text {; }
$$

- the $\mathrm{FCI}_{\mathrm{mr}}$, which encompasses the costs related to major rehabilitation and replacement needs, including costs for safety and for restoration of the asset:

$F C I_{m r}=\frac{\text { Major rehabilitation and replacement }\left(D M_{m r}\right)}{C R V}[\%]$;

- the $\mathrm{FCI}_{\mathrm{im}}$ that quantifies the costs related to recommendations highlighted in periodic CA, divided by the CRV:

$$
F C I_{i m}=\frac{\text { Maintenancerecommendations }\left(D M_{i m}\right)}{C R V}[\%] \text {. }
$$

These three indicators are combined to obtain the $\mathrm{FCI}_{\text {comp }}$ (5) calculated as the sum of the three indicators:

$$
F C I_{\text {comp }}=\frac{D M+D M_{m r}+D M_{i m}}{C R V}[\%] .
$$

The equation is used for the calculation of the Condition Index $\mathrm{CI}_{\text {comp }}(6)$ :

$$
C I_{\text {comp }}=\left(1-F C I_{\text {comp }}\right)[\%] \text {. }
$$

The $\mathrm{CI}_{\text {comp, }}$ thus, can provide a wider evaluation of economic impact of maintenance for high valuable assets. The extended version of the FCI described above is just one of the many that can be found in literature. Nevertheless, it can be considered as a good example of how this metric has been modified over the time.
Other cases in which FCI is combined with other metrics can be identified in literature. To relate the economic performance to the organisation's asset policy, the DoI encourage the utilisation of the $\mathrm{CI}_{\text {comp }}$ or the simple $\mathrm{CI}$, coupled with the Asset Priority Index (API) (U.S. Department of the Interior, 2005a): an indicator describing the relevance of the asset according to the goals of the owning organisation (U.S. Department of the Interior, 2005b, 2016). The API is a metric exploited also by private industries and other government agencies such as the National Aeronautics and Space Administration (NASA), the US Navy and the US Air Force (Mills, 2001; NASA, 2003). This approach underlies a more comprehensive calculation of the FCI, which allows to comprehend not only the performance in terms of expense to contrast the degradation phenomena, but also obsolescence process. Moreover, also issues related to the strategic value of the asset are considered.

Some other indicators, derived from the FCI, can be found in literature. Lavy et al. (2014), for instance, after discussing most effective KPIs for facilities management, identify an array of few relevant indicators for measurement of physical, functional, user satisfaction and financial performances. For the latter type of measurement, they propose the Maintenance Efficiency Indicator (MEI) (7) and the Replacement Efficiency Indicator (REI) (9). The MEI is used for assessment of efficiency of maintenance expenditure in a given year. It is calculated considering that it is not always possible to have access to all the resources needed for covering the total amount of deferred maintenance, thus a target FCI (calculated as the CI, namely 1-FCI) must be defined. A MEI of $100 \%$ means that the precise amount needed for achieving the target CI is spent. A MEI of $80 \%$ correspond to an underspending of resources. Conversely, a MEI equal to $110 \%$ indicates an overspending. Replacement is not considered in the calculation of this metric.

$$
M E I=\frac{S D M}{C I}[\%]
$$

where:

$$
\text { Spending \%on DM }(S D M)=\frac{D M(\text { actual })}{D M(\text { targeted })}[\%] \text {. }
$$

The REI, is a metric giving a dimension to the expenditure related to substitutions of components. REI below $100 \%$ means that amount spent for replacement is not enough. On the other hand, a REI greater than $100 \%$ indicates that it has been spent more than necessary. It must be considered that components must not be replaced each year, thus REI is not a continuous function, if it is considered over the facility's lifespan. This indicator describes the trend for substitution of systems at the asset level, since it considers the overall expenditure for substitution of all the components of a building. An analogous calculation at the single component level would not be significant.

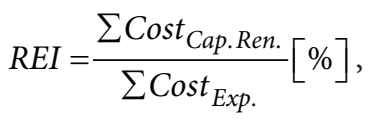

where: $\sum \operatorname{Cost}_{\text {Exp. }}$ is the actual expense for replacement of 
components and systems; $\sum$ Cost $_{\text {Exp. }}$ is the total replacement cost of expired components and systems in the same year.

MEI and REI measure how efficiently maintenance budget is spent over the years. Some other examples of combined indicators derived from FCI can be found in literature, as highlighted in in Table 1. Nevertheless, MEI and REI can be considered powerful metrics to evaluate the effectiveness of expenses for maintenance interventions (Shohet, Kot, \& Karako, 2008; Lavy et al., 2014).

\section{Computing deferred maintenance and current replacement value}

Some insights related to FCI and its utilisation can be highlighted. At first, it can be stated that this indicator should be employed jointly with a well-defined CA procedure, specifying the set of operations to be accomplished (Lavy, Garcia, Scinto, \& Dixit, 2014; U.S. Department of the Interior, 2008b, 2008a). Since FCI is a KPI that can be exploited for the evaluation of either single components or the entire building, the assessment phase is crucial to avoid biases in the decision-making process. Moreover, the calculation methodology can vary according to the objective to be achieved (Federal Facilities Council, 2001), though a standardised set of operations to compute the DM and the CRV are suggested by the US Department of the Interior. This institution adopts the FCI as a primary indicator to carry out the asset management policy (U.S. Department of the Interior, 2008b, 2008a) on its huge portfolio including real properties for a total value of more than 240 billion (U.S. Department of the Interior, 2017a). The Federal Facilities Council (2001) suggests two main assessment methodologies: the Condition Assessment Survey and the Total Life Cycle Cost Method, despite some others can be found in literature (Cable \& Davis, 2005; Bello \& Loftness, 2010). The former method encompasses a series of periodic inspections carried out to determine the current condition of properties, plants and equipment. The latter gives as outcome a forecast used to compare actual expense in maintenance to the yearly budget. Altogether, a clear explanation about algorithms to be used in calculation cannot be found (Roberts, 2009) since the methodologies are mainly explained in terms of their scope and final goals. The most critical issue seems to be the aggregation of FCI values from the components to the whole asset (Selman, 2003). Moreover, methodology for economic definition of Deferred Maintenance (DM) and Current Replacement Value (CRV) can vary remarkably because of differences in assessment methodologies adopted, composition of costs in local pricelists, regional factors and discrepancies in national labour markets (U.S. Department of the Interior, 2008b).

\section{Possible drawbacks in FCI application}

In its basic form, the FCI measures the performance of a building or a component in terms of the ratio be- tween DM over CRV. This ratio does not indicate the magnitude of deferred maintenance interventions to be executed, since the FCI is mainly led by the value of the denominator. For instance, two analogous low cost (deferred) maintenance interventions on two components characterised by very different CRV values determine substantial differences in the FCI calculation. To be more specific, the FCI will be more critical for the component featured by the lower CRV value. Nevertheless, that simple intervention could be highly critical for the component featured by the highest replacement cost. Therefore, a simple FCI calculation could not be representative of the criticality of the maintenance operation to be carried out.

$$
\begin{aligned}
& \frac{F C I_{1}}{F C I_{2}}=\frac{D M_{1} / C R V_{1}}{D M_{2} / C R V_{2}}= \\
& \frac{D M_{1} / C R V_{1}}{D M_{R} / C R V_{R} \times D M_{1} / C R V_{1}}=\frac{C R V_{R}}{D M_{R}},
\end{aligned}
$$

where: $D M_{R}(D M$ ratio $)=D M_{2} / D M_{1}$ is the ratio between $D M$ values; $C R V_{R}(\mathrm{CRV}$ ratio $)=C R V_{2} / C R V_{1}$ is the ratio between $C R V$ values.

Figure 8 and Eq. (10) show how the ratio of the FCI of two components changes according to variations in the ratio between the deferred maintenance costs (DM ratio) and the current replacement values (CRV ratio) of the components. It can be seen that for a given DM ratio the FCI ratio increases with a linear trend as well as the CRV ratio. For a given CRV ratio the FCI ratio decreases following a hyperbolic trend with the DM ratio increasing.

Accordingly, it can be stated that the FCI is a metric lead by the replacement cost of the components: a critical issue to be considered in decision-making, especially in a scarce resource condition. This characteristic may cause unreliability of comparisons among assets, a particularly relevant issue when a maintenance prioritisation strategy is being defined. However, FCI is almost always related to an asset management strategy, driving strategic investment decisions (Bello \& Loftness, 2010; Rashedi \& Hegazy, 2016; Amaratunga et al., 2000).

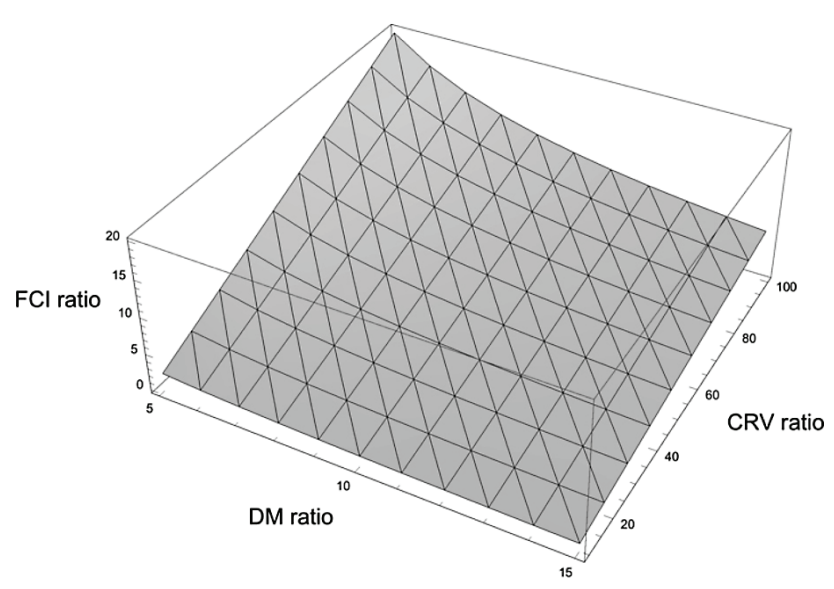

Figure 8. FCI trend according to changes in values of DM and CRV of two components 
Moreover, the FCI in its simple version does not consider other possible issue related to non-economic value, though many other aspects should be considered (technical performances, functions, relevance for community, user and owners, etc.). Thus, it is worthwhile to adjust the FCI through some parameters which allow to catch more extensive issues related to asset management. In literature some studies that relate FCI to other metrics can be found (Amaratunga et al., 2000; Roberts, 2009; Bello \& Loftness, 2010; Lavy, 2013; Parsons, 2013; Determan, Akers, Williams, Hohmann, \& Martin-Dunlop, 2015; Marzouk \& Awad, 2016), though a quantitative methodology to directly compute the dependency among performances and economic value of facilities is not clear.

Thanks to the literature review, it is possible to state that the FCI is mainly applied at the asset level. For instance, it has been widely exploited by US public department in management of wide real estate portfolios and by US real estate organisations (AAPPA, 2000; IFMA, 2008; Magellan Consulting, 2011; NASA, 2003; U.S. Department of the Interior, 2008b). When dealing with components instead of the whole buildings, the level of detail must be carefully defined. It must be considered, for instance, that when a lower breakdown level is reached, a further complexity concerning bi-stable components (e.g. bulbs, switchers, etc.) will be faced. In this case the FCI value can assume only two values, namely 0 or 1 , not giving the magnitude of the degradation trend for those components. Moreover, Uzarski and Grussing (2008) suggested to use the FCI together with a strong CA procedure and a precise calculation methodology based on updated price lists and standardised maintenance costs archives.

The FCI can also be effective in the evaluation of facility management companies (Yik \& Lai, 2005) if in the negotiation phase, a Service Level Agreement (SLA) based on the indicator is defined. In this case, the trend of FCI over the years should be registered. It should be noticed that in a FM contract the agreed FCI can be higher than zero because of a strategic decision. Conversely, in a scarce resources circumstance, the target FCI can be used for optimisation of maintenance expenses.

\section{Conclusions}

To conclude, the critical review presented in this paper identifies the main characteristics of the FCI, through a study based on a methodological approach organised in three subsequent phases:

- bibliographic research,

- bibliometric analysis,

- critical review.

However, it can be considered as a first step in the wider research on asset management processes. A conspicuous literature regarding the performance measurement of buildings has been investigated through the literature review, despite only few references are explicitly referred to FCI. In spite of that, large institutions as the US Government, exploit this metric for the definition of the asset management policy.

Concerning the calculation of the metric, it must be considered that formulas described in this article are only some of those that can be found in literature. Nevertheless, they are representative, since they are amongst the most employed by academics and professionals. A widely acknowledged computation methodology for FCI has not been defined yet, since from the first version, the metric has been revised and adapted. A standardised calculation methodology along with a clear condition assessment procedure could allow to assess portfolios more effectively and guide expenditure in maintenance, even in a scarce resource condition.

Eventually, considering the AM business process, KPIs could be categorised in two domains:

- the core domain, comprehending the set of policies and strategies carried out to achieve the main goal of the company, linked to its primary objectives;

- the non-core domain, defined as the set of policies and strategies to be accomplished in order to facilitate and foster the companies' core business.

It is clear that the FCI allows to measure the performance of non-core issues. In literature, only few attempts to link non-core performances to core business activities can be identified. An example can be found in the research regarding the improvement of teaching activities in well maintained school buildings. These studies show how a better teaching environment can affect cognitive capabilities of scholars (Determan et al., 2015; Bello \& Loftness, 2010; Amaratunga et al., 2000; Roberts, 2009). These approaches stem from a qualitative performances evaluation and give a fair result in terms of correlation between non-core performances measurement and achievement of core objectives. Therefore, it could be worthwhile to define a quantitative methodology to catch the relationship between core and non-core performances.

To summarize, it can be stated that the FCI is a reliable KPI, despite sources in literature agree on some limitations:

- it is highly influenced by the CRV, therefore it must be related to other metrics, in order to catch, for instance, the criticality of the components;

- it is not possible to spot a widely acknowledged or standardised calculation methodology;

- it cannot measure by itself the core performances of a company.

These issues will be tackled in further studies.

\section{Acknowledgements}

Authors would like to express their deepest gratitude to PhD Eng. Sebastiano Maltese for his great support during this work. We would like to thank also Rigamonti Francesco S.p.A. for funding part of the research. 


\section{Author contributions}

Fulvio Re Cecconi and Mario Claudio Dejaco conceived the research and constantly supervised the work of Nicola Moretti who developed the critical review.

\section{Disclosure statement}

We confirm that this work is original and has not been published elsewhere, nor is it currently under consideration for publication elsewhere. We have no conflicts of interest to disclose.

\section{References}

AAPPA. (2000, October). Guidelines for strategic asset management. In Facilities officers. Tertiary Education Facilities Management Association of Australasia.

Alexander, K. (1992). Facilities management practice. Facilities, 10(5), 11-18. https://doi.org/10.1108/EUM0000000002189

Amaratunga, D., \& Baldry, D. (2000). Assessment of facilities management performance in higher education properties. Facilities, 18(7/8), 293-301. https://doi.org/10.1108/02632770010340681

Amaratunga, D., \& Baldry, D. (2003). A conceptual framework to measure facilities management performance. Property Management, 21(2), 171-189.

https://doi.org/10.1108/02637470310478909

Amaratunga, D., Baldry, D., \& Sarshar, M. (2000). Assessment of facilities management performance. Facilities, 18, 258-266. https://doi.org/10.1108/02637470010348816

Attalla, M., MacDonald, C., \& Dunn, R. (2012). Asset management plan. Retrieved from https://facilities.mcmaster.ca/ app/uploads/2018/10/AssetManagementPlan-V02-Rev1027Feb2013.pdf

Bello, M. A., \& Loftness, V. (2010). Addressing inadequate investment in school facility maintenance addressing inadequate investment in school facility maintenance. Library and Information Science, Carnegie Mellon University.

Brooks, R. G. (2004, March/April). History of the facility condition index. Facilities Manager, 41-43.

BSI. (2013). PAS 1192-2:2013. Specification for information management for the capital/delivery phase of construction projects using building information modelling. The British Standards Institution, BSI Standards Limited.

Cable, J. H., \& Davis, J. S. (2005). Key performance indicators for federal facilities portfolios: Federal Facilities Council technical report number 147. Washington, D.C.: The National Academies Press. https://doi.org/10.17226/11226

Capital Asset Management - Asset Strategies. (2011). Facility Condition Index, 604, 0-2.

Dejaco, M. C., Re Cecconi, F., \& Maltese, S. (2017). Key performance indicators for building condition assessment. Journal of Building Engineering, 9, 17-28.

https://doi.org/10.1016/j.jobe.2016.11.004

Dempsey, J. J. (2006). Facility asset managemet doctrine. A Strategy for making better decisions at lower risk and costs. Federal Facilities Council's Forum, 1-7.

Determan, J., Akers, M. A., Williams, I., Hohmann, C., \& Martin-Dunlop, C. (2015). Learning space design for the ethnically diverse undergraduate classroom (pp. 1-22). The American Institute of Architects.

Douglas, J. (1996). Building performance and its relevance to facilities management. Facilities, 14(3/4), 23-32. https://doi.org/10.1108/02632779610112508
Eastman, C., Teicholz, P., Rafael, S., \& Kathleen, L. (2011). BIM handbook: a guide to building information modeling for owners, managers, designers, engineers and contractors. Hobken: John Wiley \& Sons.

Ente Italiano di Unificazione. (2018). UNI EN ISO 41011:2018 Facility management - Vocabulary. UNI Ente Nazionale Italiano di Unificazione, Milan, Italy.

Fagan, M. M., \& Kirkwood, D. M. (1997). Facility condition assessments: more than just making a list. In American Society for Healthcare Engineering 34th Annual Conference \& Technical Exhibition. Retrieved from http://kirkwoodandassociates. com/resources/CondxAss.pdf

Federal Facilities Council. (2001). Deferred maintenance reporting for federal facilities: meeting the requirements of Federal Accounting Standards Advisory Board Number 6 as amended. Washington, D.C.: The National Academies Press. https://doi.org/10.17226/10095

Geldermann, B. D., \& Sapp, D. (2007). Streamlining facility condition assessments. Retrieved from https://www.buildings. com/article-details/articleid/3590/title/streamlining-facilitycondition-assessments

General Service Administration. (2017). Federal Real Property Council (FRPC). Retrieved from https://www.gsa.gov/policyregulations/policy/real-property-policy/asset-management/ federal-real-property-council-frpc\#

Grussing, M. N., \& Marrano, L. R. (2007, July 24-27). Building component lifecycle repair/replacement model for institutional facility management. In International Workshop on Computing in Civil Engineering (pp. 550-557). Pittsburgh, Pennsylvania, United States. https://doi.org/10.1061/40937(261)65

Ho, D. C. W., Chan, E. H. W., Wong, N. Y., \& Chan, M. (2000). Significant metrics for facilities management benchmarking in the Asia Pacific region. Facilities, 18(13/14), 545-556. https://doi.org/10.1108/02632770010358088

IFMA. (2008). Asset lifecycle model for total cost of ownership management. A framework for facilities lifecycle cost management. Retrieved from http://www.ifma.org/docs/knowledgebase/asset_lifecyle_model.pdf?sfvrsn $=2$

ISO. (2014). BS ISO 55000:2014 Asset management overview, principles and terminology. Retrieved from http://www. irantpm.ir/wp-content/uploads/2014/03/ISO-55000-2014.pdf

Kaiser, H. (2009). Capital renewal and deferred maintenance programs. Alexandria, Virginia.

Kaiser, H. H. (1993). Putting the facilities work. Facilities Manager, 18-21.

Kensek, K. (2015). BIM guidelines inform facilities management databases: a case study over time. Buildings, 5(3), 899-916. https://doi.org/10.3390/buildings5030899

Kincaid, D. W. (2013, September). Standardized current replacement value calculations make facility condition index more effective. Retrieved from http://www.facilitiesnet.com/facilitiesmanagement/article/Standardi?ns-Make-Facility-ConditionIndex-More-Effective--14351? source=part

Ladiana, D. (2007). Manutenzione e gestione sostenibile dellambiente urbano. Firenze: Alinea Editrice.

Lavy, S. (2013). Practice briefing. Facility management practices in higher education buildings. A case study. Journal of Facilities Management, 6(4), 303-315. https://doi.org/10.1108/14725960810908163

Lavy, S., Garcia, J. A., \& Dixit, M. K. (2010). Establishment of KPIs for facility performance measurement: review of literature. Facilities, 28(9/10), 440-464. https://doi.org/10.1108/02632771011057189

Lavy, S., Garcia, J. A., \& Dixit, M. K. (2014a). KPIs for facility’s performance assessment, Part I: identification and categorization of core indicators. Facilities, 32(5), 256-274.

https://doi.org/10.1108/F-09-2012-0066 
Lavy, S., Garcia, J. A., \& Dixit, M. K. (2014b). KPIs for facility's performance assessment, Part II: identification of variables and deriving expressions for core indicators. Facilities, 32(5/6), 275-294. https://doi.org/10.1108/F-09-2012-0067

Lavy, S., Garcia, J. A., Scinto, P., \& Dixit, M. K. (2014). Key performance indicators for facility performance assessment: simulation of core indicators. Construction Management and Economics, 32(12), 1183-1204. https://doi.org/10.1080/01446193.2014.970208

Magellan Consulting. (2011). Facility condition index (FCI) at Austin ISD. Retrieved from http://www.assetinsights.net/ Glossary/G_Facility_Condition_Index.html\%5CnFigure

Maltese, S., Dejaco, M. C., \& Re Cecconi, F. (2017, May 29-31). Dynamic facility condition index calculation for asset management. In 14th International Conference on Durability of Building Materials and Components. Ghent, Belgium, RILEM Publications S.A.R.L.

Marzouk, M., \& Awad, E. (2016). Establishing multi level performance condition indices for public schools maintenance program using AHP and Fuzzy Logic. Studies in Informatics and Control, 25(3), 343-352. https://doi.org/10.24846/v25i3y201608

Mills, C. D. (2001). An evaluation of U. S. coast guard shore facility readiness measures. U.S. Army War College.

NASA. (2003). The NASA deferred maintenance parametric estimating guide. Retrieved from https://www.hq.nasa.gov/office/ codej/codejx/Assets/Docs/DMParametricEstimatingGuideApr03.pdf

Karanja, P., \& Mayo, G. K. (2016). State of practice for facility condition assessment. Retrieved from https://www.researchgate.net/publication/308972076_State_of_Practice_for_Facility_Condition_Assessment

Pärn, E. A., Edwards, D. J., \& Sing, M. C. P. (2017). The building information modelling trajectory in facilities management: a review. Automation in Construction, 75, 45-55. https://doi.org/10.1016/j.autcon.2016.12.003

Parsons. (2013). Dallas independent school district. 2013 Facilities condition assessment. Retrieved from http://frontburner. dmagazine.com/wp-content/uploads/2015/10/bond_foreman_ParsonsReport.pdf

Perianes-Rodriguez, A., Waltman, L., Jan, N., \& Eck, N. J. (2016). Constructing bibliometric networks: a comparison between full and fractional counting. Journal of Informetrics, 10(4), 1178-1195. https://doi.org/10.1016/j.joi.2016.10.006

Quirk, R. (2006, October). The facilities condition index as a measure of the conditions of public universities as perceived by the end users. Facilities Manager, 62-69.

Rashedi, R., \& Hegazy, T. (2016). Examining budget policies for new and existing facilities: a system dynamics approach. $\mathrm{Ca}$ nadian Journal of Civil Engineering, 43(6), 511-522, https://doi.org/10.1139/cjce-2015-0486

Roberts, L. W. (2009). Measuring school facility conditions: an illustration of the importance of purpose. Journal of Manufacturing Technology Management, 20(5), 547-567. https://doi.org/10.1108/S1479-3563(2012)000012B007

Rush, S. C. (1991). Managing the facilities portfolio: a practical approach to institutional facility renewal and deferred maintenance. National Association of College and University Business Officers.

Selman, J. R. (2003). Creating a defensible recapitalisation programme. Journal of Corporate Real Estate, 5(2), 115-125. https://doi.org/10.1108/14630010310812055

Selman, J. R., \& Schneider, R. (2004). The impact of life-cycle cost management on portfolio strategies. Journal of Facilities Management, 3(2), 173-183.

https://doi.org/10.1108/14725960510808428
Shohet, I. M., Kot, N., \& Karako, I. (2008). Clinic facility maintenance using life cycle costs principles. In CIB W070 Conference in Facilities Management (pp. 259-268). Heriot Watt University, Edinburgh.

Teicholz, E., \& Edgar, A. (2001). Facility condition assessment practices (pp. 1-14). Retrieved from http://www.graphicsystems.biz/gsi/articles/faccondassessprac_ifma_01sept.pdf

U.S. Department of Defense. (2017). U.S. Department of Defense. Retrieved from https://www.defense.gov/

U.S. Department of the Interior. (2005a). Asset priority index guidance. Retrieved from https://www.doi.gov/sites/doi.gov/ files/migrated/pam/programs/asset_management/upload/ APIGuidance092105.pdf

U.S. Department of the Interior. (2005b). Site-specific asset business plan $(A B P)$ model format guidance. Retrieved from https://www.doi.gov/sites/doi.gov/files/migrated/pam/programs/space_management/upload/Supplemental-Guidanceon-Measuring-Performance.pdf

U.S. Department of the Interior. (2008a). Asset management plan. Version 3.0. Retrieved from https://search.usa.gov/search?utf $8=\%$ E2\%9C\%93\&affiliate $=$ doi.gov\&query $=$ asset + managemen $\mathrm{t}+$ plan\& commit $=$ Search

U.S. Department of the Interior. (2008b). Policy on deferred maintenance, current replacement value and facility condition index in life-cycle cost management. Retrieved from https:/edit.doi.gov/sites/doi.gov/files/migrated/pam/programs/asset_management/upload/PolicyDMCRV53008. pdf

U.S. Department of the Interior. (2016). Deferred maintenance and capital improvement planning guidelines. Retrieved from https://www.doi.gov/sites/doi.gov/files/migrated/pam/programs/asset_management/upload/2020_dmci_program_ and_budget_guidelines_final.pdf

U.S. Department of the Interior. (2017a). Office of acquisition and property management. Retrieved from https://edit.doi. gov/pam/

U.S. Department of the Interior. National Park Service. (2012a). Park Facility Management Division Park Facility Management Division. Retrieved from https://www.nps.gov/policy/ dorders/rm-35b.pdf

U.S. Department of the Interior. National Park Service. (2012b). Park facility management division reference manual - 35B reference manual for the cost recovery for National Park Service provided utilities. Retrieved from https://www.nps.gov/policy/ dorders/rm-35b.pdf

U.S. Department of the Interior. (2017b). Retrieved from https:// www.doi.gov/

Uzarski, D. R., \& Grussing, M. N. (2008). Building condition assessment metrics: best practices. Infrastructure Reporting and Asset Management, 147-152.

https://doi.org/10.1061/9780784409589.ch20

Vanier, D. J. (2000). Asset management 101: a primer. In APWA International Public Works Congress NRCC/CPWA Seminar Series "Innovations in Urban Infrastructure" (pp. 1-15). Canada, Ottawa.

Yang, H., Yeung, J. F. Y., Chan, A. P. C., Chiang, Y. H., \& Chan, D. W. M. (2010). A critical review of performance measurement in construction. Journal of Facilities Management, 8(4), 269-284. https://doi.org/10.1108/14725961011078981

Yik, F. W. H., \& Lai, J. H. K. (2005). The trend of outsourcing for building services operation and maintenance in Hong Kong. Facilities, 23(1/2), 63-72.

https://doi.org/10.1108/02632770510575901 